\title{
A METODOLOGIA PHOTOVOICE COMO ARQUEOLOGIA DE OLHARES E SABERES INVISIBILIZADOS
}

\section{THE PHOTOVOICE METHODOLOGY IN THE FIELD RESEARCH-ACTION}

\section{Maria Alice Nunes Costa*}

Resumo: Este artigo tem como objetivo apresentar contributos teóricos e analíticos de como a fotografia pode ser uma metodologia para o "processo de tradução" cultural, relacionado ao escopo epistemológico da sociologia das ausências, proposta pelo sociólogo Boaventura de Sousa Santos e, como consequência, expandir a metodologia photovoice, criada por Wang e Burris (1997). Pretende-se ampliar a referida metodologia transformando-a em mais robusta no campo da pesquisa, ao analisar a fotografia como expressão subjetiva, de forma transdisciplinar, a partir de inflexões conectadas com a epistemologia da semiótica, do "paradigma indiciário, bem como por meio dos conceitos do "inconsciente ótico", do "paradigma indiciário" e da "fotografia-expressão", para que possam vir a colaborar para o fortalecimento metodológico de práticas dialógicas e da fotografia no campo da pesquisa-ação.

Palavras-chave: Metodologia photovoice. Comunicação visual. Ecologia de saberes. Fotografia. Diálogo.

\begin{abstract}
This article aims to present theoretical and analytical contributions of how photography can be a methodology for the cultural "translation process", related to the epistemological scope of the sociology of absences, proposed by the sociologist Boaventura de Sousa Santos and, as a consequence, expand the photovoice methodology, created by Wang and Burris (1997). It is intended to expand the referred methodology making it more robust in the research field, by analyzing photography as a subjective expression, in a transdisciplinary way, from inflections connected with the epistemology of semiotics, of the "indiciary paradigm, as well as through the concepts of the "optical unconscious", the "indiciary paradigm" and the "photography-expression", so that they can collaborate to strengthen the methodological of dialogical practices and photography in the field of action research.
\end{abstract}

Keywords: Photovoice methodology. Visual communication. Ecology of knowledge. Photography. Dialogue.

\footnotetext{
* Pós-Doutoranda em Sociologia pelo Centro de Estudos Sociais da Universidade de Coimbra (CES/UC). Doutora em Planejamento Urbano e Regional pela Universidade Federal do Rio de Janeiro (UFRJ/IPPUR). Mestre em Ciência Política pela Universidade Federal Fluminense (UFF). Professora associada da Universidade Federal Fluminense no Instituto de Arte e Comunicação Social e do Programa de Pós-Graduação em Sociologia e Direito da Universidade Federal Fluminense (PPGSD/UFF). E-mail: alicecosta.rj@uol.com.br.
} 


\section{INTRODUÇÃO}

O objetivo central deste artigo é apresentar contributos teóricos e analíticos para uma utilização mais ampliada e robusta da chamada metodologia photovoice, onde a fotografia pode ser uma alternativa epistêmica-metodológica conectada com o processo de tradução da ecologia de saberes, proposta pelo sociólogo Boaventura de Sousa Santos (2002).

Santos propõe, em especial no artigo "Para uma sociologia das ausências e uma sociologia das emergências", a importância de se identificar outros discursos ou narrativas da "ecologia dos saberes", a partir de uma crítica ao modelo de racionalidade monopolista.

Desta forma, propomos que a fotografia na photovoice seja expandida para ter em conta o seu próprio processo e contexto e, envolvê-la por novos pontos de vista conceituais, tais como da física quântica, o inconsciente ótico, a fotografiaexpressão e o paradigma indiciário. Com estes acréscimos, a photovoice pode vir a colaborar para o processo de tradução de diferentes saberes, dentro da multiculturalidade da "ecologia de saberes".

A polissemia de olhares e de interpretações podem nos ajudar a admirar os outros olhares e os outros saberes, ao invés de apenas tolerá-los. Tolerar é apenas aturar o outro como diferente, estranho ou exótico. Nesse sentido, o termo carrega, implicitamente, uma postura e uma concepção de estranhamento e, até mesmo de violência simbólica. Tolerar não aproxima. Olhar junto (ad-mirar) é diferente, porque nos aproxima do outro. Capacita-nos a traduzir e compreender o olhar do outro e, consequentemente a ampliar e trocar olhares e saberes. Nesse sentido o termo tolerar é de exclusão e, o termo admirar, é de inclusão. Admirar é ver, olhar e mirar junto com o outro. Admirar é exercitar o olhar da estética e da ética da alteridade.

Desta forma, neste artigo, apresento a metodologia photovoice, os seus limites e possibilidades para que ela possa ser estendida, estética e epistemologicamente, com o intuito de estar interconectada com uma fotografia atenta e perplexa, por meio do diálogo sobre diferentes experiências. 


\section{A FOTOGRAFIA PARA AS CIÊNCIAS HUMANAS E SOCIAIS}

Nesta primeira parte do artigo, esclareço que não pretendo esgotar ou mesmo discutir sobre as referências teóricas do papel da fotografia como instrumento para a pesquisa na área da Sociologia. Há muitos e sérios estudos sobre a fotografia como instrumento de análise sociológica e, mais ainda, no campo da antropologia visual. Ao esclarecer isto, ressalto que a importância deste artigo está em apresentar uma metodologia recentemente nova; e, a partir disto, tecer contributos teórico-analíticos para a expansão e robustez desta metodologia denominada de photovoice por Wang \& Burris, para o campo da sociologia das ausências, trabalhada pelo sociólogo Boaventura de Sousa Santos (2002).

Apenas para ilustrar alguns exemplos do papel da fotografia nas ciências sociais, apresento como referência John Collier Jr., que foi um dos pioneiros na análise da fotografia como instrumento científico. Durante os anos da Grande Depressão norte-americana, a partir das fotografias realizadas sob o patrocínio da Farm Security Administration, Collier chegou a cunhar o termo "photo-elicitation" em um de seus trabalhos (COLLIER JÚNIOR, 1957). O termo, traduzido para o português como "foto-elicitação", nos remete etimologicamente (elicitar-ção) à ação e ao efeito de elicitar/evocar, extrair, obter respostas com perguntas, estimular para desencadear questões ou, ato de evocar resposta ou reação de alguém. Com o termo "photo-elicitation", Collier insere a fotografia como metodologia de análise fenomenológica para a condução de entrevistas científicas, como estímulo complementar a outros métodos de pesquisa qualitativa, no campo das ciências sociais, em particular na antropologia.

Cito também Howard Becker (1974), com sua destacada contribuição à sociologia visual, quando sugeriu que deveríamos pensar na fotografia como um instrumento muito maior do que a sua capacidade de registrar, na medida em que as fotografias podem comunicar mais do que textos escritos. Becker teve uma preocupação com a veracidade das imagens fotográficas. Em seu artigo "Do Photograph Tell the Truth?" (BECKER, 1978), Becker afirma que as dúvidas em relação à verdade sobre a fotografia possuem as mesmas dimensões sobre a indagação de quaisquer métodos ou técnicas de análise científica. Atualmente, este fato é mais gritante com os avanços tecnológicos de programas de software não só para fotomontagem, mas também para manipular vozes, fatos, dados estatísticos, 
dentre outros.

De acordo com o sociólogo José de Souza Martins, em seu livro "Sociologia da Fotografia e da Imagem" (MARTINS, 2016, p. 26), todos os métodos e técnicas de investigação estão sujeitos à indagações e, por esta razão, a multiplicidade de técnicas precisam atuar de forma complementar. Segundo Martins, os sociólogos abertos ao diálogo com a Antropologia e a História - sabem da importância do silêncio, do olhar e do sonho para a compreensão da realidade social. Conforme o autor:

Portanto, a sociedade se move, também, a partir do indizível e do invisível. Resta saber se no verbalizável há indícios do indizível, se na fala há evidências do silêncio. Ou se no visível há indícios do invisível. (MARTINS, 2016, p. 27).

A sociologia anteriormente foi denominada de "física social", em 1822, pelo positivista Augusto Comte (1798-1857), na medida em que pretendeu estudar os fenômenos sociais à mesma luz dos elementos astronômicos, físicos, químicos e fisiológicos. Na época, seu olhar era compreender a sociedade e as relações sociais, como sujeitas às mesmas leis naturais e invariáveis da física clássica. Em outras palavras, a física clássica influenciou sobremaneira a lógica de como pensamos, onde a realidade física trata a natureza como um movimento retilíneo, uniforme e mecanicamente observável, como verdade objetiva.

Contudo, a física clássica sofreu uma mudança de paradigma que convida a sociologia a voltar a refletir nos seus próprios métodos, objetivos e interpretações. A emergência da mecânica e da física quântica e a sua ausência de um resultado único, fecham as portas para a realidade determinística, ao deixar de ser possível prever - por questões intrínsecas da natureza, qual o efeito provocado por uma determinada causa; e, qual a causa que originou um certo efeito. Passamos a observar uma sucessão de eventos, mas estes, não são totalmente determinados pelos eventos anteriores e tornam-se dependentes do que, de quem e de que forma são experienciados. O princípio da incerteza de W. K. Heisenberg (1959), nos fenômenos quânticos, consegue nos mostrar algo sobre a superestimação da causalidade: uma (in)cognoscibilidade empírica e teórica sobre as causas que geraram os efeitos.

Em 1924, o físico Broglie sugeriu a ideia de que as partículas podiam ser explicadas como ondas, o que experimentalmente se comprovou. Daqui, nasce o 
conceito da dualidade onda-partícula. Quando um objeto é visto como uma partícula é possível saber-se tudo sobre ele num certo momento. Quando é visto como uma onda, existe apenas uma probabilidade de que ele tenha certas propriedades.

O termo "dualidade" onda/partícula ou energia/matéria é tentadora ao nosso raciocínio, na medida em que fomos forjados a pensar sempre de maneira dicotômica e binária. Contudo, devemos nos alertar que as duas dimensões da realidade, para a física quântica, coexistem de maneira dinâmica, conexa e interativa. São complementares. No universo quântico, a natureza dos elementos se alterna e estes, assim, funcionam de maneira equilibrada.

Ao contrário da lógica e da construção do pensamento da física clássica, uma maior complexidade do mundo passa a ser percebida. Começou-se a debater que, desta forma, a realidade não é necessariamente uma e objetiva; mas que, a subjetividade pode ter um papel determinante na sua construção.

No contexto do olhar e da fotografia, é interessante verificar como os fenômenos quânticos têm um importante lugar: a luz que chega aos nossos olhos como à lente da câmara fotográfica como uma onda, ao interferir com eles, ela colapsa para um valor concreto, tornando-se uma partícula, constituindo assim a criação de uma realidade que, antes dessa interferência, não estaria determinada.

A fotografia está em completa conexão com as angústias da incerteza e com a alteração de paradigma científico clássico e fundamentalista. Primeiramente, com a fotografia, acreditamos ser possível observar o mundo como ele é. Ver com os próprios olhos pessoas e lugares que nunca conhecemos. Todavia, numa segunda análise, esta objetividade é apenas ilusória: atrás de uma câmera, existe alguém que toma a decisão de captar aquele momento, naquele ângulo, com aquela determinada exposição. Mais uma vez, a promessa de encapsular uma realidade absoluta é falhada.

A imagem fotográfica subentende uma relação "emaranhada" entre uma objetividade e uma subjetividade. Ao captar algo numa fotografia, tal como na física quântica, fica encapsulado apenas um momento em certas condições, que é muitas vezes extrapolado como contendo a realidade completa. Este paralelo sugere a necessidade de explorar a transdisciplinaridade da fotografia.

No dia-a-dia, as pessoas pensam que a fotografia é objetiva, porque a imagem que se revela em uma foto "parece" ser visualmente idêntica ao que os 
olhos viram. Contudo, a fotografia não é apodítica. A visão é uma construção sensorial e mental, sujeita a filtros culturais, psicológicos e sociais, onde quem fotografa não apenas informa, mas faz a foto interpretando o que os seus olhos veem. Acrescento Didi-Huberman sobre as alterações do olhar, quando percebemos ou sentimos a evidência do "outro" que também nos olha: "O que vemos só vale - só vive - em nossos olhos pelo que nos olha. Inelutável paradoxo em que o ato de ver só se manifesta ao abrir-se em dois." (DIDI-HUBERMAN, 2010, p. 29).

Portanto, o papel do observador que mede uma partícula na física quântica é análogo a do sujeito por detrás da câmera fotográfica: o que é registrado é apenas parte da realidade e depende de quem a registra. $\mathrm{O}$ que ambos os cenários põem em causa é a acessibilidade do total da realidade, através dos mecanismos disponíveis para acessá-la. Na fotografia podemos ver aquilo que não é; e, vermos aquilo que parece ser, na medida em que o meu olhar se entrelaça com o que me olha e no que foi me olhado. Esta é uma das complexidades da relação entre olhar, ver e fotografar. Podemos inferir, de acordo com Schopenhauer, que todos nós seres humanos, tomamos os limites de nosso próprio campo de visão como os limites do mundo. Conforme este filósofo:

\begin{abstract}
O mundo é minha representação. Essa é uma verdade que vale em relação a cada ser que vive e conhece, embora apenas o ser humano possa trazêla à consciência refletida e abstrata. $\mathrm{E}$ de fato o faz. Então nele aparece a clarividência filosófica. Torna-se the claro e certo que não conhece sol algum e terra alguma, mas sempre um olho que vê um sol, uma mão que toca uma terra. Que o mundo a cercá-lo, existe apenas como representação, isto é, tão somente em relação a outrem, aquele que representa, ou seja, ele mesmo. (SCHOPENHAUER, 2005, p. 43).
\end{abstract}

Neste sentido, a fotografia é uma representação e uma ideia de como olhamos e produzimos sentidos ao que nos olha e ao que olhamos. Ao fazer uma fotografia, estamos inconscientemente representando o que percebemos pelos sentidos, pois a imagem fotográfica é uma representação análoga do mundo e da realidade; portanto, é uma ideia do que temos do mundo. Não é o mundo, nem tampouco a realidade. A realidade do mundo é uma representação no qual, em comunidade, convencionalmente damos sentido; uma interpretação; e, um "ponto de vista". 


\title{
3 A METODOLOGIA PHOTOVOICE: LIMITES E POSSIBILIDADES
}

A metodologia photovoice foi criada, nos anos 90, pelas pesquisadoras Caroline Wang e Mary Ann Burris ${ }^{1}$, como uma metodologia de pesquisa participativa e de ação associada à fotografia. Foi criada com base na promoção da saúde pública, desenvolvimento comunitário e educação, tendo como referência a educação crítica e dialógica do educador brasileiro Paulo Freire; bem como da fotografia documental.

As concepções de Paulo Freire (1983) influenciaram sobremaneira a photovoice, na medida em que os seus pressupostos partem da necessidade de uma pedagogia dialógica e emancipatória. A luta dele na educação se concentrou em transformar sujeitos oprimidos em cognoscentes e autores da sua própria história, por meio de uma práxis transformadora. Portanto, suas ideias caem "como uma luva" na metodologia photovoice. Segundo Daniel Meirinho (2016, p. 113) a metodologia photovoice também foi influenciada pela teoria feminista, em relação à apreciação da experiência subjetiva feminina e ao compromisso político do reconhecimento do protagonismo político das mulheres.

Quanto à influência da pesquisa participativa na metodologia photovoice, trago como referência a "pesquisa-ação" descrita pelo intelectual francês e naturalizado brasileiro, Michel Thiollent (1988), no sentido em que acredito que a pesquisa-ação é a que mais se aproxima da photovoice, na medida em que seu principal objetivo é alavancar mudanças conjuntamente com a comunidade. A pesquisa-ação é uma pesquisa social de base empírica, associada com uma ação e resolução de problemas coletivos, ao lado da pesquisa participante ou participativa. Thiollent resume os principais aspectos desta pesquisa-ação, que mesmo não explicitadas na metodologia photovoice, elas podem ser elencadas, intrinsecamente:

\begin{abstract}
"a) há uma ampla e explícita interação entre pesquisadores e pessoas implicadas na situação investigada; b) desta interação resulta a ordem de prioridade dos problemas a serem pesquisados e das soluções a serem encaminhadas sob forma de ação concreta; c) o objeto de investigação não é constituído pelas pessoas e sim pela situação social e pelos problemas de diferentes naturezas encontradas nesta situação; d) o objetivo da pesquisaação consiste em resolver, ou, pelo menos, em esclarecer os problemas da situação observada; e) há, durante o processo, um acompanhamento das decisões, das ações e de toda a atividade intencional dos atores da
\end{abstract}

\footnotetext{
1 Carolina Wang é afiliada da Escola de Saúde Pública da Universidade de Michigan (USA) e, Mary Ann Burris da Escola de Estudos Orientais e Africanos da Universidade de Londres (UK).
} 
situação; f) a pesquisa não se limita a uma forma de ação (risco de ativismo): pretende-se aumentar o conhecimento dos pesquisadores e o conhecimento ou o "nível de consciência" das pessoas e grupos considerados." (THIOLLENT, 1988, p. 16).

Segundo Wang e Burris, a metodologia photovoice, pode ser desenvolvida em qualquer campo de atuação social, que envolva problemas e/ou questões comunitárias. Consiste em três principais objetivos:

1. Possibilitar que as pessoas registrem e reflitam as preocupações de sua comunidade;

2. Promover o diálogo crítico e o conhecimento sobre questões importantes, por meio de discussões em grandes ou pequenos grupos, sobre fotografias capturadas pelas próprias pessoas da comunidade; e,

3. Alcançar os formuladores de políticas públicas e incentivar a adoção de políticas formuladas pela própria comunidade, por meio de exposições fotográficas coletivas.

Ressalto que, neste artigo, não questionarei sobre todas as etapas da metodologia photovoice. Concentrarei a minha atenção nos "encontros", onde a conexão entre diálogo e fotografia é produzida.

A photovoice é singular porque parte da premissa da reunião de membros de uma comunidade para debater e atuar sobre questões críticas, apresentadas através de fotografias e narrativas. Os participantes capturam imagens que significam algo para eles, em relação a temas específicos da pesquisa ou por questões que possam vir a surgir nos encontros e são colaboradores ativos em todas as fases. Depois que as fotografias são realizadas, os participantes remontam para sessões de debate sobre as imagens capturadas. Finalmente, o grupo decide, coletivamente, como selecionar fotografias e alavancar o projeto photovoice, no sentido de encorajar mudanças dentro da comunidade, através da exibição das fotografias.

De acordo com Wang e Burris, a photovoice oferece a oportunidade para que os membros da comunidade possam documentar criativamente suas preocupações e, simultaneamente, agirem como "catalisadores de mudança". A proposta é possibilitar que as pessoas possam identificar, representar e melhorar a vida coletiva da comunidade, em especial a saúde de mulheres, por meio da relação entre a fotografia e diálogo (WANG; BURRIS, 1997, p. 369). Para as autoras, a metodologia photovoice ultrapassa a linguagem e as barreiras tradicionais de 
comunicação que, muitas vezes, impedem os membros de um grupo em expressar suas preocupações, na medida em que as fotografias - realizadas pelos participantes dos grupos - despertam para novos olhares sobre questões que os afetam.

Depois de cumprir os seus objetivos na comunidade local ou no grupo, o método photovoice no seu aporte da fotografia documental, cinge-se presentemente ao registro, memória e difusão de informações, atribuindo a ela um passado e um futuro. Portanto, estarei focada com o presente, onde os diálogos e as fotografias são mobilizados. Desta forma, me importa a construção cultural, a interpretação e o que significado que são produzidos na "zona de contato" entre pesquisadores e comunidade.

Quanto à importância da imagem fotográfica, chamo a atenção de que estamos numa espécie de "Era Imagética". Hoje, a maioria da população mundial possui uma máquina fotográfica acoplada em seus telemóveis. Segundo os dados do Relatório produzido pela GSMA Intelligence (Londres, 2019) sobre a economia móvel, 5,1 bilhões de pessoas possuem algum tipo de aparelho móvel, número equivalente a $67 \%$ da população mundial ${ }^{2}$. O artista holandês Erik Kessels apresentou em uma instalação artística, a impressão de um milhão de fotos postadas gratuitamente no Flickr, Facebook e no Google durante um período de 24 horas. Essa instalação foi primeiramente apresentada no Foam Amsterdam (2011), intitulada "Photography in Abundance" e, depois, em outras cidades na Europa e em Nova York, com o título "24HRS in Photos", com o objetivo de demonstrar como nós, internautas, somos bombardeados com imagens diariamente.

Desta forma, importa a nossa maior vigilância epistemológica sobre a leitura das fotos que realizamos e vemos, na medida em que esse bombardeio tem deixado a nossa "vista cansada" e, acabamos por banalizar as imagens, as naturalizando sem reflexão. Portanto, precisamos de uma nova acuidade reflexiva visual, diante deste cenário. E a metodologia photovoice precisaria destacar a importância para a habilidade de compreendermos a imagem visual e as genuínas preocupações sociais e culturais, que são produzidas por meio das fotografias nesta metodologia.

\footnotetext{
2 Para o intuito de comparação, menos de $15 \%$ do mundo possui os recursos financeiros ou humanos necessários para a implementação de políticas e planos de água, saneamento (esgotamento sanitário) e higiene, segundo a OMS no Global Status Report 2019:"UN-Water Global Analysis and Assessment of Sanitation and Drinking-Water (GLAAS) 2019, report National systems to support drinking-water, sanitation and hygiene.
} 
Apesar da metodologia photovoice se utilizar da fotografia documental, quem realiza as fotografias são as pessoas, os grupos e a comunidade que vive a realidade territorial e cultural; portanto, as fotografias são o resultado dos sujeitos da história local. E este ponto de vista merece uma especial atenção, pois possui potencialidades sobre a abstração do olhar de quem vive as experiências e trocas de saberes locais, que é - na sua maioria das vezes - bem distante do olhar do pesquisador.

Quanto aos resultados obtidos pela metodologia photovoice, conforme levantamento, realizado em 2019, via internet de artigos acadêmicos, constatei que a metodologia é nova e, os artigos publicados no Brasil - em sua maioria - são a partir do ano 2012.

Desta maneira, por experiência própria e, por meio dos dados da pesquisa doutoral de Meirinho (2016), apresento brevemente alguns limites da metodologia photovoice, para em seguida, apresentar os contributos que possam fortalecer esta metodologia para o "processo de tradução", sugerido pela sociologia das ausências. Dentre essas limitações em territórios socioeconômicos vulneráveis, destaco:

Número de transferência de resultados de pesquisa ainda pequeno;

Recursos financeiros escassos para a impressão das fotografias realizadas pelos participantes dos grupos que vivem em situação de vulnerabilidade econômica, bem como para a produção de espaços culturais que promovam a exposição fotográfica para a divulgação e transferência dos resultados;

Restrição ao engajamento de jovens, em ambientes de risco e violência;

$\checkmark \quad$ Dilemas éticos, como a invasão de privacidade ao realizar fotografias;

$\checkmark$ Backgroud bastante limitado de experiências em atividades educacionais dialógicas;

$\checkmark$ A metodologia não apresenta questionamentos em relação às diferenças culturais e de poder ou sobre os conflitos, preexistentes entre investigador e comunidades ou grupos sociais;

Nem tampouco, problematiza a intervenção de pesquisadores em comunidades que vivem em periferias, sob vulnerabilidades socioeconômicas.

Além disso, a metodologia não traz nenhuma teoria sobre como ler e 
compreender imagens fotográficas. Desta forma, o maior contributo deste artigo é trazer os conceitos epistemológicos da sociologia das ausências para a metodologia photovoice, bem como acrescentar alguns paradigmas interdisciplinares para 0 "processo de tradução" proposto pela sociologia das ausências.

\section{CONTRIBUTOS PARA EXPANDIR A PHOTOVOICE NO "PROCESSO DE TRADUÇÃO"}

Há um olhar que sabe discernir o certo do errado e o errado do certo. Há um olhar que enxerga quando a obediência significa desrespeito e a desobediência representa respeito. Há um olhar que reconhece os curtos caminhos longos e os longos caminhos curtos. Há um olhar que desnuda, que não hesita em afirmar que existem fidelidades perversas e traições de grande lealdade. Esse olhar é o da alma. (BONDER, 1998).

O sociólogo português Boaventura de Sousa Santos propõe três procedimentos sociológicos para a tentativa de fazermos emergir pensamentos, ideias e experiências invisibilizadas pelo conhecimento hegemônico, para serem visíveis: a sociologia das ausências, das emergências e o processo de tradução, que sintetizaremos a seguir.

Ao abordar a relação entre a sociologia das ausências e das emergências, Santos (2002) afirma que o que não existe, na verdade, é produzido para tal. São realidades transformadas em ausentes ou invisíveis por meio do silenciamento, da supressão ou da marginalização construída pela racionalidade hegemônica. Desta forma, o autor clama por transformar questões, ações, produções, experiências que estão invisíveis pelo colonialismo e poder hegemônico, em visíveis. Para tanto, é importante que, por meio da imaginação epistemológica e democrática, possamos criar zonas de contato, envolvendo um diálogo multicultural e intercultural, entre diferentes universos de saberes.

Segundo o autor, a racionalidade da modernidade ocidental criou fronteiras abissais entre o conhecimento científico (dado como verdade absoluta), excluindo outros conhecimentos e saberes e os considerando como residuais, irrelevantes e frágeis. Esta conduta arrogante acabou por desperdiçar experiências, vivências e conhecimentos que não levaram a lugar nenhum, a não ser a perpetuação da opressão produzida para tal intuito.

A partir dessa premissa, Santos propõe uma teoria ou um processo de tradução, capaz de criar inteligibilidade mútua entre experiências possíveis e 
disponíveis. O autor afirma que é necessário um enorme esforço de tradução, na medida que é um trabalho complexo que envolve diversos agentes com diferentes práticas e culturas. Desta forma, o "processo de tradução" não consiste em componentes puramente técnicos, pois envolve uma predisposição de trabalho intelectual, político e democrático. E o autor questiona: O que traduzir? Entre o quê e quem? Quem traduz? Quando traduzir? Traduzir com quais objetivos? (SANTOS, 2002, p. 268).

Segundo Santos, o trabalho de tradução é um processo que envolve uma constelação de saberes e práticas, em meio de "zonas de contato" e campos sociais onde diferentes mundos-da-vida normativos, práticas e conhecimento se encontram, chocam e interagem. Santos atenta sobre as dificuldades do processo de tradução, na medida em que toda argumentação se assenta em postulados, axiomas e regras. Portanto, é necessária uma constante prudência e vigilância epistemológica e democrática; pois, no interior de cada comunidade epistêmica, as argumentações são aceitas como evidentes para todos.

Dentre outras dificuldades do processo de tradução, Santos (2002) destaca também a voz do silêncio. No processo de tradução, a importância da escuta do silêncio é de suma importância. O silêncio não é passividade. Pode ser expressão latente e pulsante. Nem toda opressão e violência são capazes de tornar seres vivos em apáticos ou subservientes à vida que os subalterniza ou os escraviza. Nos silêncios há vozes e expressões que podem subverter o que tem sido considerado marginal, ignorante, exótico e/ou improdutivo. Cabe a nós, pesquisadores, tornar inteligível as vozes que têm sido ocultadas por nossa arrogância científica.

Os silenciamentos contêm a dimensão do não-dito ou o que foi colocado em silêncio. Portanto, silenciar-se é uma forma de comunicar. A importância do silêncio tem sido melhor analisado nas artes, na música, no teatro, na dança e na psicologia e/ou na psicanálise, na medida em que concebem o silêncio como linguagem, indício, gesto, movimento e espaço de significação que reverbera na estética, na melodia e na produção de sentidos e significados. (BURKE, 1995).

Assim, ao envolver a metodologia photovoice na epistemologia da sociologia das ausências, considero que a dimensão da fotografia nesta metodologia pode ser expandida ao encapsular a subjetividade dos indivíduos que fazem as fotografias nas suas especificidades. Desta forma, acrescento três fundamentos analíticos à 
análise de fotografias na metodologia photovoice, que podem ser conectados dialeticamente, no sentido de alavancar a fotografia, como um método para o processo de tradução de culturas e saberes.

O fato de interconectar a fotografia com o diálogo, levou-me a questionamentos da importância da fotografia, enquanto substrato de análise de pesquisa. Neste caminhar intelectual, fui me encontrando com várias pistas para compreender a transdisciplinaridade do ato fotográfico e me reencontrei diante da semiótica pierceana. A maneira como raciocinamos é uma questão de exercício de certos hábitos de inferência cognitiva do ato de pensar. E, aqui, destaco a inferência abdutiva de Charles Peirce (1834 -1914). Na maioria das vezes, as pesquisas descrevem, em suas metodologias, as inferências indutivas e dedutivas, descuidando da inferência abdutiva; e, é ela quem nos leva à novas ideias, na medida em que esta inferência possui caráter explicativo e intuitivo (surpresa), que introduz uma nova ideia (criatividade e inovação). Essa atenta observação, da operação mental abdutiva para Pierce:

[...] advém-nos como um lampejo. É um ato de introvisão (insight), embora de uma introvisão extremamente falível. É verdade que os diferentes elementos da hipótese já estavam em nossas mentes antes; mas a ideia de reunir aquilo que nunca tínhamos sonhado reunir que lampeja a nova sugestão diante de nossa contemplação (PEIRCE, 1997, p. 226).

Quando nos debruçamos fortemente numa tarefa de difícil resolução e que precisamos resolver, a partir de nossas experiências de vida - seja intelectual ou manual - focamos a nossa percepção e "transpiramos" ao cogitar hipóteses de soluções, a partir de nossos instintos humanos. Nosso raciocínio, em operação de inferência abdutiva, passa a observar com atenção pistas, sintomas, a testar conclusões, às quais colocamos em suspeição. Novamente, voltamos a testar as conclusões geridas em nossa mente, associamos novos palpites, até chegarmos a uma situação nova, em que encontramos uma melhor explicação para resolver o problema.

Esse tipo de raciocínio cognitivo por durar segundos, vai depender da complexidade do problema em que nos confrontamos e o tempo, intrinsicamente, solicitado. Segundo Pierce, sobre a intuição e a abdução, afirma:

Seja como for que o [ser humano] tenha adquirido sua faculdade de adivinhar os caminhos da natureza, certamente não o foi através da lógica crítica e autocontrolada (...) Parece-me que a formulação mais clara que 
podemos fazer a respeito [...] consiste em dizer que o [ser humano] tem uma certa Introvisão (Insight), não suficientemente forte para que esteja com mais frequência certo do que errado, mas forte o suficiente para que esteja, na esmagadora maioria das vezes (...). Esta Faculdade pertence, ao mesmo tempo, à natureza geral dos Instintos, assemelhando-se aos instintos animais, na medida em que estes ultrapassam os poderes gerais de nossa razão (...) a frequência relativa com que está certo é, no conjunto, a coisa mais maravilhosa de nossa constituição (PEIRCE, 1997, p. 221) ${ }^{3}$.

Para Pierce, há inferências lógicas de causalidades que se fazem presentes pelos vestígios de nossa existência, transformando algo ausente, em presença significada. Esta articulação da imagem/semelhança na teoria semiótica nos permite compreender os indícios da imagem fotográfica, em sua complexidade transdisciplinar e na sua força comunicacional. A partir deste questionamento, encontro-me diante do "paradigma indiciário" (método clínico de pesquisa ou semiologia médica), baseado também na lógica da "inferência abdutiva" de Charles Pierce.

Quanto a este "paradigma", temos uma interessante trajetória epistemológica. Sua origem remonta ao trabalho desenvolvido por Giovanni Morelli (1816-1891). Morelli era médico e, quando também historiador de arte, utilizava o pseudônimo de Ivan Lermolieff, como sendo um crítico de arte russo. Como historiador de arte criou um método de crítica de arte (depois chamado de método Morelliano), em que observava minuciosamente os pormenores, muitas vezes negligenciados nas pinturas.

Outro médico, atento ao método indiciário foi Joseph Bell (1837-1911), médico e professor escocês da Universidade de Edimburgo (Reino Unido), considerado o primeiro cirurgião científico escocês e pioneiro da ciência forense. Em suas aulas, enfatizava a supra importância na observação atenta nos detalhes, antes de se fazer um diagnóstico.

Morelli e, principalmente, Joseph Bell influenciaram sobremaneira outro médico e romancista: Arthur Conan Doyle (1859-1930). Conan Doyle foi aluno de Joseph Bell na Universidade de Edimburgo, a quem deve a escrita de seu primeiro livro "Um Estudo em Vermelho" (DOYLE, 2006), onde pela primeira vez apareceu o personagem-detetive Sherlock Holmes, que desvendava enigmas de crimes policiais, narrados pelo personagem Dr. Watson. O método do detetive Holmes se dava pelos mesmos meios ensinados por Bell: a abdução, a observação e a

\footnotetext{
${ }^{3}$ Substituí propositalmente o termo homem, utilizado por Pierce, por ser humano.
} 
descrição minuciosa de pequenos detalhes, a partir de indícios aparentemente imperceptíveis.

Em 1914, o médico neurologista e psicanalista Sigmund Freud (1856-1939), escreveu no ensaio "O Moisés de Michelangelo" (FREUD, 1996, p. 9-19), afirmando que sua técnica psicanalítica se apoiou no método de Morelli, em que observava coisas secretas e ocultas, a partir de aspectos menosprezados ou inobserváveis.

Mais recentemente, temos um importante fôlego intelectual para a teorização do paradigma indiciário na História, que pode sinalizar e sistematizar conexões valiosas para o processo de tradução na fotografia: o paradigma indiciário de Carl Ginzburg, em particular na sua obra "Mitos, emblemas, sinais: morfologia e história" (GINZBURG, 1989), resultado de sua análise sobre a importância das pistas e do farejo, para os caçadores primitivos. Nesse sentido, Ginzburg traz à luz a proposta do método interpretativo freudiano indiciário, conectado com as ideias de Giovanni Morelli, e a inferência abdutiva de Charles Pierce, sobre a importância dos sinais, resíduos e dados marginais, para a pesquisa e análise de dados e documentos históricos.

Ao descrever a relevância indiciária contida nos sinais, traços e vestígios, Ginzburg conecta-se com a semiótica de Charles Pierce, a partir da categorização do signo indiciário, o que torna reveladora para a leitura de imagens fotográficas. A fotografia aponta indícios e sinais a serem revelados, coletivamente.

A análise dos sinais, pistas e índices na fotografia não é uma decodificação de significados fixos, na medida em que os significados são produzidos por meio do próprio processo de leitura. Esses significados são encontrados por meio da arqueologia da leitura de sinais e rastros produzidos nas imagens fotográficas em interação com o processo dialógico, no intuito de vir à tona o que a imagem significa para cada grupo social ou comunidade.

Nesta trajetória epistêmica indiciária, acrescentamos e incorporamos o "inconsciente ótico", tratado por Walter Benjamim (1892-1940). Para o autor, a fotografia é capaz de liberar o inconsciente ótico que existe em todos nós, pois possui estreitas relações com o inconsciente pulsional. Ao provocar um operador da câmera fotográfica à busca e captura de uma imagem, que tenha algum significado para ele, este ato direcionará a sua ótica para algo que possa realmente o despertar. Desta forma, acaba por liberar emoções encapsuladas em seu inconsciente. Essa 
provocação o leva para a captura de uma imagem que é, por essência, muito maior do que a sua/nossa cegueira sistêmica. Portanto, a pulsão do desejo em capturar imagens sobre algo ou um tema que impacte a sua sensibilidade, o fotógrafo libera energias, emoções, medos, dores, sonhos e pulsões do movimento de seu inconsciente. Em síntese e, conforme Walter Benjamin (1994, p. 94):

\begin{abstract}
Depois de mergulharmos suficiente fundo em imagens [...]. Apesar de toda a perícia do fotógrafo e de tudo o que existe de planejado em seu comportamento, o observador sente a necessidade irresistível de procurar nessa imagem a pequena centelha do acaso, do aqui e agora, com a qual a realidade chamuscaria a imagem, de procurar o lugar imperceptível [...]. A natureza que fala à câmara não é a mesma que fala ao olhar; é outra, especialmente porque substitui a um espaço trabalhado conscientemente [...]. Percebemos, em geral, o movimento de um homem que caminha, ainda que em grandes traços, mas nada percebemos de sua atitude na exata fração de segundo em que ele dá um passo. A fotografia nos mostra essa atitude (...). Só a fotografia revela o inconsciente ótico, como a psicanálise revela o inconsciente pulsional (grifo nosso).
\end{abstract}

A memória de quem fotografou emerge, tornando potência de assimilação consciente daquilo que estava latente e obscuro, sendo capaz de produzir novos sentidos à representação sobre a realidade vivida. De outra forma, a fotografia no método photovoice poderá estar atenta para o "inconsciente ótico", na medida em que ele pode revelar detalhes nas imagens e aceder a um olhar analítico, que muitas vezes são ocultados pelo olhar desatento e cansado.

Neste diálogo transversal, recorri a André Rouillé (2009) a partir do seu conceito de "fotografia-expressão". O autor reconhece que a fotografia não é apenas um documento, na medida em que está embutida de valores da realidade social. $O$ autor interpela sobre o olhar interpretativo de quem fotografa e, daquilo que fotografa, pois escreve com a luz suas vidas e experiências. Ao fotografar, o operador da câmera expressa uma forma de ver e olhar, a partir do campo da cultura, descortinando a sua realidade subjetiva. Esta expressividade das imagens acaba por se tornar fruto de uma construção sensível, nas esferas interpessoais e intrapessoais, a partir de uma subjetividade que se entrelaça entre a razão e a emoção. O autor sustenta que a fotografia é um processo, um "evento" vivo e catalizador de experiências relacionais.

Portanto, a imagem fotográfica, produzida como expressão, pressupõe uma interação sensível com a realidade de quem a observa e a interpela. Não apenas produzindo imagens, mas utilizando-se de seu imaginário, para expressar a sua subjetividade autônoma e livre para transformar o que olha, em comunicação visual. 
Neste sentido, cria-se uma estética relacional (BOURRIAUD, 2007), a partir de encontros intersubjetivos, que podem ser interpretados coletivamente.

Neste aspecto relacional, o processo dialógico estabelecido a partir das fotografias, pode vir a colaborar para o processo de tradução e o fortalecimento de zonas de contato, dentro do escopo da sociologia das ausências. Fotografias realizadas pelos membros da comunidade vis-à-vis a diálogos construtivos, podem fazer emergir diferenças culturais, perguntas, respostas, emoções, afetos que, "num espaço-tempo determinado se encontram em concorrência para dar sentido a uma determinada linha de ação" (SANTOS, 2002, p. 268). Portanto, a Fotografia é uma possibilidade para traduzir fenômenos inviabilizados, transformando-os em representações e informações cognitivas, que possam dialogar e magnetizar "zonas de contato" entre cientistas e pessoas, grupos sociais, comunidades que têm outras experiências. Portanto, uma foto nunca é apenas uma foto.

E, para finalizar, acrescento - a partir das minhas experiências com a metodologia photovoice, outro ingrediente, que considero poderoso: a Meditação "Miksang" (DUBOSE, 2015; QUICK, 2020)4. Ela pode ser realizada em qualquer momento dos Encontros ou, juntamente com exercícios fotográficos ${ }^{5}$. Tem o intuito de acalmar a mente para deixar o nosso olhar mais contemplativo para fazer as fotografias. "Miksang" provém da etimologia tibetana para designar "olho bom", que não incorpora no adjetivo nenhum sentido qualitativo ou maniqueísta. A ideia é meditar para deixar a mente ao alcance da natureza inata, inteligente, serena e presente. Neste estado, o fotógrafo pode capturar uma imagem sem se preocupar com questões técnicas de fotografia, como foco, luz ou enquadramento. O que vale não é o resultado em si, mas o prazer de fotografar e transmitir a emoção ao compartilhar a imagem com outras pessoas ${ }^{6}$.

\footnotetext{
${ }^{4}$ Há várias publicações e sites que descrevem sobre a fotografia contemplativa (Miksang).

${ }^{5}$ Antes de fazer as fotos sobre as questões sociais erigidas nos encontros, proponho também alguns exercícios lúdicos de fotografia.

${ }^{6}$ Por analogia ao termo "Miksang", encontrei a noção de "Musement" de Charles Pierce, no sentido de tranquilizar a mente e criar possibilidades para o surgimento do pensamento abdutivo, por meio de um jogo lúdico do ato de pensar, de acordo com Barrena (2003).
} 


\section{CONSIDERAÇÕES FINAIS}

Neste artigo, analisei como a metodologia photovoice pode ser expandida para melhor analisar experiências individuais e coletivas, por meio da relação simbiótica entre os processos fotográfico e dialógico. Vi ser um dispositivo que pode ser capaz de empoderar os seus utilizadores/participantes, na medida em que são eles que escolhem o que fotografar e, quando, por meio de interações relacionais. Aos investigadores permite aceder à perspectiva dos participantes sobre o fenômeno em estudo, mesmo em grupos mais vulneráveis da população, por ser acessível a todos aqueles que sejam capazes de realizar uma fotografia, independentemente de possuírem o hábito de ler ou escrever.

Neste caminhar do processo de tradução, vimos que a fotografia é uma representação e uma ideia de como olhamos e produzimos sentidos ao que nos olha e ao que olhamos. Ao contemplar o que nos parece ser diferente, fotografamos e podemos traduzir uma ecologia de saberes. A fotografia é uma disciplina transdisciplinar que é capaz de dialogar com a arte e a estética, com a técnica, a física quântica e também como instrumento de análise sociológica, antropológica e psicológica, por ser um vetor de grande complexidade, na medida em que olhamos o mundo através de um espelho. O reflexo em um espelho não é de modo algum o que parece ser. Essa é a metáfora do mundo que olhamos.

Acreditamos que a denominada metodologia photovoice possui possibilidades de se transformar e se constituir efetivamente em uma metodologiaepistêmica para o processo de tradução - de que nos fala Boaventura de Sousa Santos, quando associada à visão transdisciplinar da fotografia, por meio dos conceitos analisados neste artigo: o paradigma indiciário; o inconsciente ótico; e, a fotografia como expressão transdisciplinar à luz da epistemologia da física quântica, onde a subjetividade do observador é fundamental.

A fotografia pode ser capaz de desvendar experiências consideradas nãointeligíveis ou subalternizadas, saberes ocultos e emergir novos conhecimentos rumo à uma revelação dirigida à emancipação social, mesmo que de forma utópica, ou por um longo caminho.

As fotografias acrescentam ao sentido da audição o da visão, expandindo a consciência sensorial, na medida em que a fotografia é um poderoso meio de 
comunicação social e visual. Ela estimula novos pensamentos e memórias, mas não necessariamente aquelas contidas na imagem presente da fotografia. É capaz de aceder o inconsciente ótico, tornando o invisível em visível e, deste modo, possibilitando a compreensão de fenômenos e de experiências reveladoras. Assim sendo, quando Boaventura Santos nos pergunta com quais objetivos traduzir, respondemos que, se essas experiências forem traduzidas, utilizando-se da metodologia photovoice alargada e ampliada, elas poderão ser capazes de serem compartilhadas, criando redes de conexões.

Cada ser e cada grupo social possui sua narrativa cultural. Não existe um olhar certo ou errado. Assim como não existe uma cultura ou saber certo ou errado. Nossos olhares são limitados e, para olharmos melhor, precisamos de outros olhares. São as constelações e a cosmologia do olhar que nos permite ampliar nossos horizontes e poder dialogar com outros olhares. Portanto, todos os olhares são complementares, pois há inúmeras coisas que um indivíduo não consegue ver ou não quer ver. Cada um olha de acordo com a sua imaginação e a sua cultura.

Desta forma, existe aquilo que não queremos ver ou aquilo que não conseguimos olhar. Assim, tornamos invisível o que não podemos olhar. Esta invisibilidade traduz-se no silenciamento do olhar. Este silenciamento, por um lado, pode ser derivado de uma opressão inconsciente instituída que não permite a sua expressão ou, por utro lado, pode existir deliberadamente, como manifestação cultural, afetiva, emocional e eloquente de um determinado grupo social.

A nossa visão é estética, física, social, cultural e biologicamente restrita e limitada. A consciência dessa limitação e incompletude é simétrica à consciência de que existe uma complexa pluralidade de olhares, visões, perspectivas e saberes. Essa consciência da existência de uma constelação de olhares e pontos de vista diferentes podem nos aproximar, em alguma medida e, em algum momento, do olhar e do conhecimento e das experiências do outro, que é diferente e complementar à nossa visão.

\section{REFERÊNCIAS}

BARRENA, Sara Fernández de. La creatividad en Charles S. Peirce: abducción y razonabilidad. 2003. 452 f. Tese (Doutorado em Filosofia) - Facultad de Filosofía y Letras, Universidad de Navarra, Pamplona, 2003. Disponível em: http://www.unav.es/gep/TesisDoctorales/TesisBarrena.pdf. Acesso em: 14 nov. 2019. 
BECKER, Howard. Art as collective action. American Sociological Review, [S. I.], v. 39, n. 6, p. 767-776, 1974.

BECKER, Howard S. Do photographs tell the truth? Afterimage, [S. I.], v. 5, n. 8, p. 9-13, 1978.

BENJAMIN, Walter. Pequena história da fotografia. In: BENJAMIN, Walter.

Discursos interrumpidos I. Lisboa: Relógio D`Água, 1994. p. 61-83.

BONDER, Nilton. A alma imoral. Rio de Janeiro: Rocco, 1998.

BOURRIAUD, Nicholas. Estética relacional. São Paulo: Martins Fontes, 2007.

BURKE, Peter. A arte da conversação. São Paulo: UNESP, 1995.

COLLIER JÚNIOR, John. Photography in anthropology: a report on two experiments. American Anthropologist, [S. I.], v. 59, n. 5, p. 843-859, 1957. Disponível em: https://anthrosource.onlinelibrary.wiley.com/doi/abs/10.1525/aa.1957.59.5.02a00100. Acesso em: 12 jan. 2017.

DIDI-HUBERMAN. O que vemos, o que nos olha. São Paulo: Editora 34, 2010.

DOYLE, Arthur Conan. Um estudo em vermelho. Tradutora: Ligia Cademartori. São Paulo: FTD, 2006.

DUBOSE, Julie. Miksang publications. [S. I.], 2015. Disponível em: http://miksangpublications.com/. Acesso em: 21 mar. 2018.

FREIRE, Paulo. Pedagogia do oprimido. Rio de Janeiro: Paz e Terra, 1983.

FREUD, Sigmund. O Moisés de Michelangelo. In: FREUD, Sigmund. Edição standard brasileira das obras psicológicas completas de Sigmund Freud. Tradução: J. Salomão. Rio de Janeiro: Imago, 1996. p. 9-19. Disponível em: https://edisciplinas.usp.br/pluginfile.php/4247154/mod_resource/content/1/Mois\%C3 \%A9s\%20de\%20Miguelangelo\%20\%5BFreud\%20-\%201914\%5D.pdf. Acesso em: 21 mar. 2018.

GINZBURG, Carlo. Mitos, emblemas, sinais: morfologia e história. São Paulo: Companhia das Letras, 1989.

HEISENBERG, Werner. Physics and philosophy. Great Britain: Public Domain, 1959.

MARTINS, José de Souza. Sociologia da fotografia e da imagem. São Paulo: Contexto, 2016.

MEIRINHO, Daniel. Olhares em foco: fotografia participativa e empoderamento juvenil. Covilhã: LabCom.IFP, 2016. 
PEIRCE, Charles Sanders. Semiótica. São Paulo: Perspectiva, 1997.

QUICK recap, monthly theme and upcoming outing info. Nalanda Miksang Moose Jaw, [S. I.], 2020. Disponível em: https://nalandamiksangmoosejaw.wordpress.com/. Acesso em: 21 mar. 2018.

ROUILLÉ, André. A fotografia: entre documento e arte contemporânea. São Paulo: Senac, 2009.

SANTOS, Boaventura de Souza. Para uma sociologia das ausências e uma sociologia das emergências. Revista Crítica em Ciências Sociais, [S. I.], v. 63, p. 237-280, 2002.

SCHOPENHAUER, Arthur. O mundo como vontade e representação. Tradução: Jair Barboza. São Paulo: UNESP, 2005.

THIOLLENT, Michel. Metodologia da pesquisa-ação. São Paulo: Cortez, 1988.

WANG, C.; BURRIS, M. A. Photovoice: concept, methodology, and use for participatory needs assessment. Health Education and Behavior, [S. I.], v. 24, n. 3, p. 369-387, 1997. 